\title{
The chronicles and annalistic sources of the early mamluk circassian period
}

Leiden-Boston, Brill, Islamic History and Civilisation, 67, 2007, 477 p.

[ISBN 978-9004-156265]

\section{Anne Troadec}

\section{(2) OpenEdition}

\section{Journals}

Édition électronique

URL : http://journals.openedition.org/beo/215

DOI : 10.4000/beo.215

ISBN : 978-2-35159-318-9

ISSN : 2077-4079

Éditeur

Presses de l'Institut français du Proche-Orient

\section{Édition imprimée}

Date de publication : 1 octobre 2010

Pagination : 162-164

ISBN : 978-2-35159-170-3

ISSN : 0253-1623

\section{Référence électronique}

Anne Troadec, "The chronicles and annalistic sources of the early mamluk circassian period », Bulletin d'études orientales [En ligne], Tome LIX | octobre 2010, mis en ligne le 01 octobre 2011, consulté le 22 septembre 2020. URL : http://journals.openedition.org/beo/215; DOI : https://doi.org/10.4000/beo. 215

Ce document a été généré automatiquement le 22 septembre 2020.

(c) Institut français du Proche-Orient 


\section{The chronicles and annalistic sources of the early mamluk circassian period}

Leiden-Boston, Brill, Islamic History and Civilisation, 67, 2007, 477 p. [ISBN 978-9004-156265]

\section{Anne Troadec}

\section{RÉFÉRENCE}

The chronicles and annalistic sources of the early mamluk circassian period. Leiden-Boston, Brill, Islamic History and Civilisation, 67, 2007, 477 p. [ISBN 978-9004-156265]

I Il n'existait pas jusqu'à la parution de ce livre de travaux de synthèse sur l'historiographie de la période mamelouke circassienne comparables à ceux d'U. Haarmann et D. P. Little pour les débuts de l'époque mamelouke, et ce malgré le fait que cette période, inaugurée par l'avènement du sultan al-ẓāhir Barqūq (784-91, 792-801/1382-9, 1390-9), coïncide avec l'émergence d'une nouvelle génération d'historiens (p. 4-6). Adoptant la méthodologie établie par Little pour les sources du règne d'al-Malik al-Nāșir Muḥammad $b$. Qalāwūn dans An Introduction to Mamluk Historiography, Wiesbaden, 1970, l'A. cherche à établir de façon minutieuse les liens de dépendance entre les principales chroniques de l'époque circassienne. Afin de mettre en évidence la nature des liens entre les différents textes, il procède à une comparaison mot-à-mot des différentes versions des récits des événements pour trois années choisies : 778/1376-7, qui vit l'assassinat d'al-Ašraf Šacbān ; 796/1390-1, marquée par la révolte de Mințāš contre les partisans de Barqūq en Syrie ; et 804/1401-2 qui représente un tournant historiographique, avec la disparition du récit de celui qui avait servi jusque là de source majeure aux autres chroniqueurs, Ibn al-Furāt. Cette «Microapproche de l'historiographie nous permet d'identifier les similitudes et les variations entre les différentes chroniques afin d'expliquer la complexité des emprunts qui forme la base de chacune d'elle» (p. 7). Tous les éléments qui permettent de faire sens sont minutieusement décortiqués (variantes de vocabulaire, idiosyncrasies, stratégies de 
sélection, ordre de compilation etc.) et présentés dans une argumentation rigoureuse. Outre une appréciation de l'origine et de la genèse des récits, ce travail permet de reconsidérer l'ensemble du matériel historiographique, afin de réévaluer notre compréhension des événements.

2 L'élément que l'A. a choisi d'utiliser comme unité de base pour son analyse est ce qu'il nomme l' «individual report", identifié dans l'enchaînement des événements historiques, qu'il classe en quatre grandes catégories et numérote : PMA : Political and Military Affairs, RL : Religious Life; SHM : Social History/Miscellany et FA : Foreign Affairs.

3 L'A. a travaillé principalement sur les textes édités, mais il s'est appuyé également sur les manuscrits, particulièrement le texte inédit d'un auteur anonyme (Ğawāhir al-Sulūk, MS British Museum Or. 6854), un manuscrit rédigé de la main de l'historien damascène Ibn Qāḍi Šuhba (Chester Beatty MS 4125) grâce à qui sont conservés certaines annales d'Ibn Duqmāq (al-Muntaqā min TārīH Ibn Duqmāq) et d'Ibn al-Furāt (al-Muntaqā min TārīH Ibn al-Furāt), ainsi que deux versions manuscrites du 'Iqd al-Ǧumān d'al-'Aynī (Amhet III 2911/B2 et Dār al-Kutūb MS 1584 tārīH), l'un holographe et l'autre de la main de son frère Ahmad $b$. Ahmad et de son disciple al-AHmīmī. Ces deux derniers manuscrits seraient en fait deux résumés de la version originale du 'Iqd, ce qui remet en cause le point de vue de l'éditeur des textes (al-Qarmūț, éd. Beyrouth, 1989) mais ne tranche pas de façon définitive la question (p. 41-45).

Le livre s'organise en trois chapitres, correspondant aux trois années sélectionnées pour la comparaison. Chaque chapitre passe en revue les différentes chroniques, classées selon que les auteurs sont contemporains des événements ou plus tardifs. Au sein de ces deux groupes, l'auteur distingue les auteurs égyptiens (une majorité écrasante) des auteurs syriens (Ibn Ḥiğğī et Ibn Qāḍī Šuhba principalement). Il sont suivis d'annexes très conséquentes qui reprennent les « individual reports ».

5 Le principal apport de l'ouvrage est de mettre en évidence les sources les plus originales qui ont été le plus copiées : pour la Syrie le TārïH Ibn Hiğğği, et pour l'Egypte, la Nuzhat al-Anām d'Ibn Duqmāq, le TārīH al-Duwal d'Ibn al-Furāt pour le début de la période, puis plus tard le Kitāb al-Sulūk d'al-Maqrīzī et le 'Iqd al-Ǧumān d'al-'Aynī, qui offrent des contributions originales à l'histoire du début du IX $/ \mathrm{XV}^{\mathrm{e}}$ siècle.

Outre l'établissement des liens de dépendance entre ces big five et les autres sources, l'autre grand mérite de cet ouvrage est de fournir quantités d'éléments sur la fabrique de l'histoire. Au- delà du simple rapport d'emprunt entre deux textes, l'A. identifie un éventail d'outils appartenant à l'atelier de l'historien: par exemple, la présence de matériel commun à Ibn Hुaldūn, Ibn al-Furāt, Ibn Duqmāq pour l'année 778 suggère, sans que l'A. ne tranche, soit l'utilisation de sources orales (les événements sont encore frais quand Ibn Hुaldūn arrive au Caire en 784), soit le recours à des sources écrites déjà disponibles (p.19). La grande proximité des textes d'Ibn Hुaldūn, de Zayn al-Dīn Ṭāhir et d'al-'Aynī ainsi que les variations de détail qu'ils présentent pour les aHbār de l'année 793 concernant la Syrie laissent penser qu'ils se sont appuyés sur des sources syriennes aujourd'hui disparues, et qu'il existait en Syrie un certain nombre d'auteurs pas particulièrement célèbres mais dont les travaux ou les récits oraux furent néanmoins utilisés par leurs contemporains ou par les historiens tardifs (p.95). D'autres auteurs ont utilisé des témoignages directs (Ibn Tag̉nī Birdī livre des données concernant les tribulations de son père en Syrie du Nord) ou indirects (des sources orales pour Zayn alDīn Țāhir et al-'Aynī). Concernant les techniques d'écriture, l'A. relève le «travail 
éditorial » réalisé par certains historiens à partir de plusieurs sources : Ibn al-Furāt insère ses propres données dans des éléments identifiés comme étant d'origine duqmaqienne ; pour recréer des faits historiques, al-Maqrīzī emprunte un ou plusieurs éléments d'un report pour les utiliser comme composantes d'un autre récit opérant ainsi un transfert d'éléments narratifs entre deux reports, certes liés entre eux, mais néanmoins distincts (p. 53). Certains auteurs semblent prendre une grande liberté avec le "consensus historiographique», cette vision des faits que partagent une majorité d'auteurs. Ibn Iyās insère des éléments fictionnels, et l'auteur du Ğawāhir semble plus intéressé par la forme de son récit et son effet littéraire que par le contenu historique qu'il peut fournir (p. 80). Ces incohérences historiques chez certains auteurs ainsi que l'insertion d'éléments de fiction apparentent le texte historiographique au texte littéraire, ce qui conduit à aborder la question du public à qui était destiné ses ouvrages. Or, et c'est l'une des grandes limites du livre, les conditions de réception des ouvrages historiques ne sont pas étudiées (sauf de façon allusive dans la conclusion, $\mathrm{p}$. 194-196) alors qu'il s'agit d'une question centrale lorsqu'on analyse les différentes variantes entre les manuscrits (à qui sont destinées les différentes versions d'un texte ?). Par ailleurs, la multiplication de certains genres historiques à l'époque considérée (Dayl, Muntaqā) réclamait de mener une réflexion théorique plus approfondie sur cette forme particulière de textes.

7 Une autre question qui n'est pas traitée en tant que telle, alors qu'elle apparaît comme une ligne de fracture majeure dans l'analyse, est celle de la différence entre les auteurs égyptiens et les auteurs syriens. Sur le plan formel, l'A. évoque une historiographie mamelouke, typiquement égyptienne, mais parfois représentée par des auteurs d'origine syrienne, comme Ibn Ḥiǧğì, dont la chronique est très différente, par exemple de l'œuvre du damascène Ibn Șașra (p. 131). L'étude des stratégies de sélection d'Ibn Qādī Šuhba montrent que cet auteur a cherché à construire un texte qui ne soit pas marqué par son identité syrienne, mais puisse être diffusé sur tout le territoire mamelouk, en opérant une fusion entre trois grands groupes de sources qu'il a utilisées, dont certaines ont été débarrassées de leur stricte "syrianité ». La question cruciale est celle de l'accès à l'information. L'A. donne des indications intéressantes : pour l'année 793, le récit d'Ibn al-Furāt concernant les événements de Syrie présente de nombreuses divergences avec les sources syriennes, Ibn Hịğğì et Ibn Șașra. Certaines défaites du camp loyal à Barqūq sont camouflées en victoires, rien n'est dit de la sympathie de certaines franges de la population syrienne à l'égard des partisans de Mințāš etc. Ibn al-Furāt s'est appuyé pour construire son récit sur les courriers reçus au Caire relatant les événements de Syrie. Il est probable qu'ils aient été manipulés par le $n \bar{a}$ 'ib de Damas en personne Yalbuğā al-Nāṣīīi (dont la duplicité à l'égard du sultan est relevée par d'autres auteurs, notamment Ibn Hुāldūn), afin d'éviter la colère du sultan, ou plus vraisemblablement de différer son départ vers la Syrie.

8 Sur ce thème, comme sur d'autres, le défaut majeur de l'ouvrage est son absence de synthèse véritable. Il fourmille de détails très précis sur la genèse des différentes sources, mais il est regrettable qu'aucune synthèse ne vienne en montrer les apports. L'A. a du mal à dépasser ce qui a déjà été établi par les études déjà existantes sur les chroniques (articles de l'Encyclopédie de l'Islam, travaux de Haarman, Little, Van Steenbergen, Bauden, Reisman) et la conclusion de 7 pages ne permet pas de traiter en profondeur les questions soulevées. 
9 Enfin, on regrettera le choix des citations en translittération, ce qui rend la lecture pénible, surtout dans le cas de citations des plusieurs lignes.

10 Toutefois, on peut considérer que l'appel lancé par Li Guo, « Mamluk historiographical Studies : The State of Art », MSR, 1, 1997, p.15 sur la nécessité de mener des études sur l'historiographie mamelouke comme préalable aux travaux historiques a été partiellement entendu.

\section{AUTEURS}

\section{ANNE TROADEC}

Université Saint-Joseph / EPHE 